\title{
Interview
}

\section{In conversation with Stanley Smith}

\author{
Hugh Freeman interviewed Dr Smith recently
}

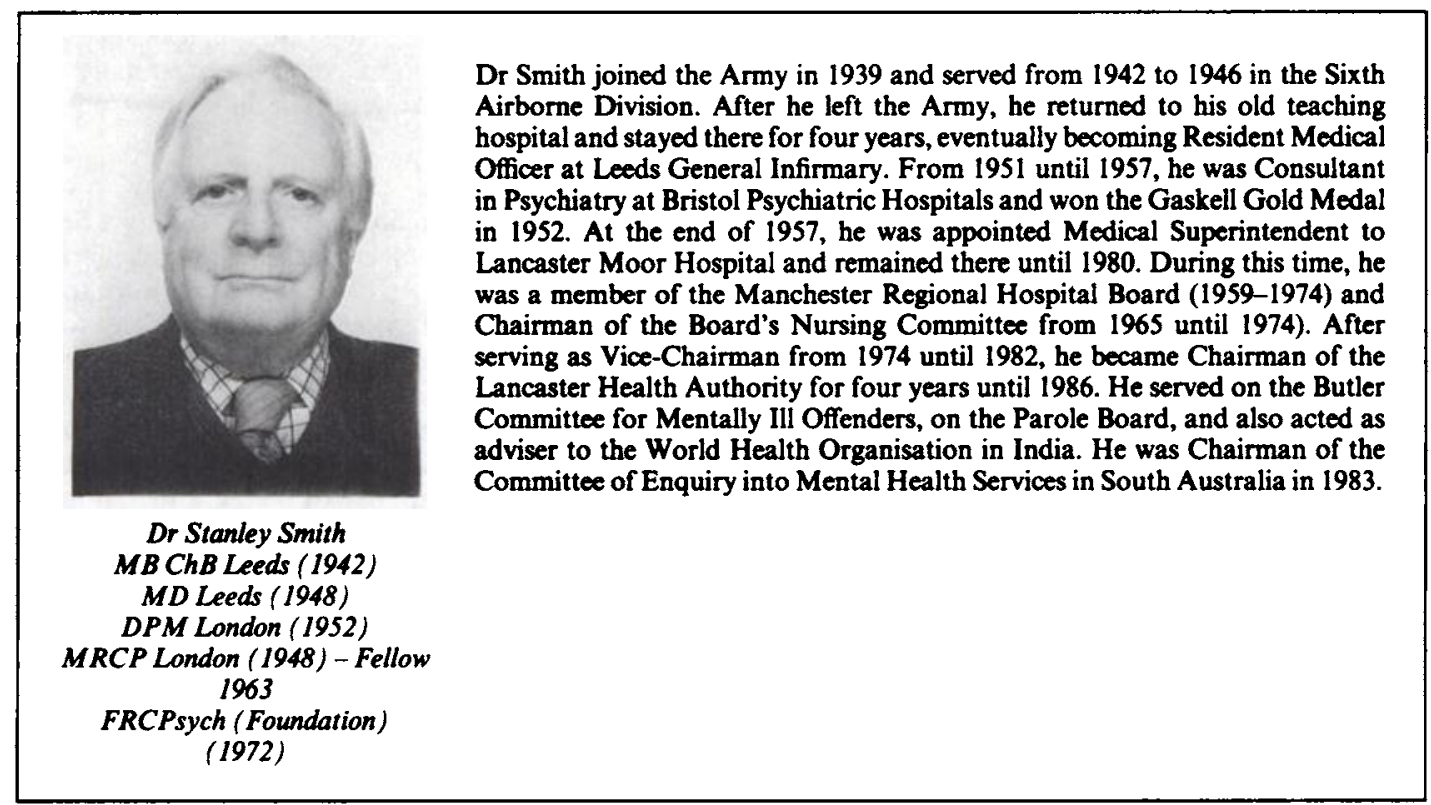

Could you tell me first if there was anything in your early life or background that might have led you in the direction of psychiatry?

No, I don't think there was. When I went to the University of Leeds in the mid-1930s, I had only a vague notion about the subject. It was probably not a good time to start a University course in medicine-or indeed many other subjects. A lot of the pre-clinical teaching seemed irrelevant to me, and in those days, three years passed before any clinical work began and patients became a reality. Compounding these difficulties were the everincreasing and threatening war noises from Germany. Cinema newsreel images of bands, of flags, of marching men, of raucous demands for this, that, or the other - these became more visible to me and more anxiety-producing than anatomy, physiology, or biochemistry.

\section{How did this atmosphere affect you?}

Together with many other students, I joined the Territorial Army from the University Officers' Train- ing Corps. This was why, although I had already started as a clinical medical student, I found myself at the outbreak of the War in 1939, in the Army, firstly as a Second Lieutenant in the King's Own Yorkshire Light Infantry and, almost by sleight of hand, a Lieutenant in a Light Anti-Aircraft Regiment, into which the light infantry had been transformed. I also found myself in northern France, awaiting the expected German onslaught, though we had only two proper anti-aircraft guns; the rest of our armament was made up of a miscellany of Bren and First World War machine guns. Such lack of preparedness wasn't at all unusual then, and one wonders what modern 'investigative' reporters would have made of it. We were young enough to believe in the rightness of our cause, though, and that one day we would be properly armed; the agony and 'miracle' of Dunkirk were some months away. However, as the Germans refused to attack that autumn, the rest of 1939 drifted by and sometime in November, the Army Council decided that medical students who had started clinical work should be returned immediately to their various medical schools. They must have believed either 
that we would make better doctors than soldiers or, more likely, that eventually, we would be more useful that way. So after qualifying and doing six months 'on the house', I returned to the Army and spent the next four and a half years in it, in the UK, North-West Europe, and finally Palestine.

Was there anything in your wartime experiences that you would like to mention particularly?

After returning to the Army, I went to Liverpool for a course in Tropical Medicine, then to a Gas course in the south, and then I joined the Airborne Forces, in which I remained until the end of the War. Although all Airborne medical people had to be trained as parachutists, I was first posted to an Air Landing Regiment as a Regimental Medical Officer. From this Regiment, the coup de main group was chosen which captured the bridges over the River Orne and the Caen canal-a pivotal success for the British Forces early on D-Day in 1944. I accompanied the Regiment into Normandy, Holland, and finally over the Rhine, heading for the Baltic, where finally we met up with the Russians.

\section{Did you have psychiatric casualties?}

The Airborne Forces were very carefully selected and in the first two engagements, there were few psychiatric casualties. These were evacuated to nearby medical facilities, where I remember hearing of the successful early treatment of 'battle' shock, of hysterical reactions, and of the all-pervading anxiety syndromes that occurred in these conditions. On our return to England, I became a DADMS - junior staff officer - and helped in the formation of a special Airborne Brigade, which most people knew was destined for the Far East, for the final push on Japan. Fortunately for us, the War ended and we found ourselves in Palestine - before the 'troubles' there really gathered force. For a very short while, I rejoiced in the rank of Lt-Colonel with a field ambulance, but even before the ink was dry on the paper promoting me, I was back in England, 'demobbed', clad in a brand new government-issue suit, and starting to look around for a job.

\section{What happened when you left the Army?}

I'm sure the story can be replicated by many people. There was a far better system for returning soldiers, including doctors, home than after the First World War, and very good re-training facilities were open to us, if we wished to take them. I certainly did. I wanted to obtain a good grounding in general medicine, so the objective of returning as a supernumary registrar to my old teaching hospital in Leeds was to obtain the MRCP and if possible, a Doctorate in Medicine. I stayed there four years, finally as the Resident Medical Officer at Leeds General Infirmary. At the time, there weren't many choices of jobs, particularly in Leeds, and some of us began to look at specialties other than general medicine. Among possible choices was psychiatry. A University department had recently been established in Leeds, with $D$. $R$. MacCalman as the Nuffield Professor, and his senior lecturer at the time was Robert Orton. Both were enthusiastic and, in their way, persuasive teachers. I was in close contact with both, particularly in their 'rounds' of their ward, and often accompanied either of them when they visited other patients in the medical wards, on request. Later, $H$. V. Dicks succeeded MacCalman and almost certainly, he finally confirmed my decision to try and specialise in psychiatry.

\section{What happened then?}

I had an enormous piece of luck in landing a Senior Hospital Medical Officer position in psychiatry at Barrow Hospital in Bristol. Such posts were to disappear later, but they helped many of us to get experience in the subject, obtain as much training as possible, and-unlike many training posts in University departments - allow us to bring up our families (at least financially). In about a year and a half, I was a consultant in psychiatry, and a couple of years after, an Assistant Lecturer at the University of Bristol. The Head of Department was R. E. Hemphill.

Can you tell me about your time in Bristol?

I spent about seven years there, mainly as a consultant. It was a highly interesting and certainly a "learning' time. As well as being Head of the University Department, Hemphill was the Medical Superintendent of the mental hospital, and I found him very stimulating, provocative, and innovative. He and Max Reiss were associated with research in a PsychoEndocrine laboratory in the grounds of Barrow Hospital. The unit produced many papers on endocrine relationships with mental and psychological syndromes of one sort and another, and most of the psychiatrists first found themselves in print in papers emanating from that laboratory. It was an excellently equipped and well staffed enterprise; a physicist, for example, working there went on to a high management position with the Electricity Generating Board.I would personally have difficulty, though, in defining in more detail the association of endocrine dysfunction and psychiatric anomalies, as this emerged in the work of this laboratory. My recollection, probably faulty, is that later association with the Medical Research Council provided a more fruitful outlet for its activities than the local Department of Psychiatry.

\section{How did the endocrine work start in Bristol?}

This was some time before I got there - a collaborative venture between Hemphill and Reiss. It must 
have been a mighty tour de force to build up this facility and staff it at that time, just after the war. Most of the psychiatrists at Bristol were associated with the work, but in a very restricted way - mainly for psychiatric diagnosis on patients who were having endocrine evaluation.

I met Reiss in the summer of 1956 when I was at Netley, because he was also investigating Army cases at the time. There was a great deal of enthusiasm about the work and a belief that this was going to lead to a tremendous breakthrough in psychiatry, particularly in schizophrenia, but in the end it never happened.

No. Both Hemphill and Reiss were great enthusiasts, but it was often difficult to deduce any relationship between endocrine abnormalities, as shown by the laboratory, and specific mental disorder. I should add that I also helped to prepare psychiatrists for taking the Bristol DPM by organising lectures and clinical meetings. Barrow was fairly small-about 350 beds - but it had out-patients in the hospital, as well as at Bristol Royal Infirmary, and a fairly close connection with its much larger associated mental hospital. This was then called Fishponds, now Glenside; it was looked after at the time and for many years after, by Don Early, whose later work on community care was showing its early origins, even then. I also had the good fortune to work in Barrow with Christopher Turton, who ran the EEG department, Edward Hare, Edward Turner, who became Head of the Department of Forensic Psychiatry at the Clarke Institute in Toronto, and others who later distinguished themselves in various parts of the world.

I think that when you were in Bristol, you did some of the early work on day hospitals. I remember a paper you wrote, which was one of the first pieces that I had read on the subject.

That's right. Since the Bristol Mental Health service consisted of two hospitals - a fairly large one, Fishponds, on the north side of the city and a smaller one, Barrow, on the south side, out-patient clinics were held at both these and, by Hemphill at the Bristol Royal Infirmary. The future day hospital, in Grove Road, was almost in the centre of the city and roughly mid-way between the two main mental hospitals. Like many others later, the building was an erstwhile small mansion which adapted easily and well to our requirements. It was accessible, unlike Barrow, and rapidly became a very busy facility. Clinics, treatment sessions of all types, out-patient ECT, and indeed all examinations and therapies extant at the time were carried out there. I believe it was the second to be established in Britain, after the London Marlborough Day Hospital. Those of us who worked there thought it was a very worthwhile project.
What happened next? What year did you come to Lancaster?

At the end of 1957, I took on the position of Medical Superintendent to Lancaster Moor Hospital. The role of the superintendent was being hotly debated at the time, though there were still plenty of such posts. It was clear to me that superintendents had daily access to committee members, particularly the chairman, and to top people such as the Hospital Secretary and other heads of departments, so that any good or progressive ideas that one had could be transmitted quickly to the people who could put them into action. I tried to become a conduit for my colleagues, few in number though they were, and for nursing and indeed any other staff whose ideas might otherwise not have seen the light of day.

\section{How did you find it when you arrived there?}

A very large Victorian hospital with out-buildings, for instance, some single-storey wards that were more recently constructed. There were nearly 2,800 patients and a number of the wards housed more than 100 each. For this, there was a miniscule medical staff, with one of the senior consultants, A. A. Martin, also responsible for the towns of Ulverston and Barrow some 50 miles away, and a Deputy Medical Superintendent who eventually was asked to take on Blackpool and its environs.

I remember you writing in one of your papers of a "grotesque paucity" of doctors in mental hospitals.

Yes. Looking back, the position was unbelievable, yet at the time we thought that at least we were making some headway. Many of the wards were locked and the hospital had a security officer whose job was to stop patients venturing outside, though some years later, we had to have security to stop outsiders coming in!

\section{What was the general feeling? How was morale?}

Among all staff, particularly the nurses, there was a widespread desire for change - for reducing the ward populations, for opening up the entire hospital with a general unlocking of gates and doors. This was in line with events and practice in many parts of the country by then. There was a lot of hope-generally realised in time - that many patients could easily look after themselves in the town and in shops - but that was so far untested in those days in Lancaster.

The main problem was sheer numbers. Compounding Lancaster Moor's many patients, on the other side of the town was the Royal Albert Hospital, which housed well over 1000 of the mentally subnormal, as they were then called. The effect of patients freely moving about became worrying for many of the residents of the two smallish towns-Lancaster had about 50,000 people and Morecambe, four miles 
away, varied around 70,000 , depending on the number of visitors. This was particularly so since the great majority of the patients from either hospital had nothing at all to do with the district. Both groups originated from all parts of Lancashire and, in the case of the Royal Albert, from far beyond. In the event, little happened; patients and the 'normal' population mixed very well, with few incidents and hardly any increase in shop-lifting, for example. There were plenty who, on any evaluation, had no reason to be in mental hospitals. Often their homes had long since disappeared, as indeed had their relatives, but few local authorities were willing to accept that they had any responsibility for the community settlement of these ex-residents. Running down numbers in mental hospitals was always a difficult, slow, and in my experience, not a very rewarding activity.

Was there a climate of opinion then about the future of mental hospitals?

Enoch Powell referred to them as Leviathans. It was the beginning of the plans-later basically unchanged by subsequent governments - to run down mental hospitals to extinction, if possible, and to treat mental illness in the community, but if people had to go into hospital, to make sure their stay was short and their discharge fairly rapid. The whole situation was described by Kathleen Jones as being the product of three revolutions. The first was the administrative revolution begun by Bell at Dingleton before the War, opening doors and generally unlocking the institutions, encouraging greater freedom and more group and community mixing. Secondly, there was the legislative revolution of the 1959 Mental Health Act, which stressed the possibility of treatment in the community or brief hospital admissions if necessary. The third one was the introduction of the phenothiazine drugs, which appeared to help many symptoms in a quite remarkable way and to reduce the tension and agitation experienced by so many schizophrenic patients. Of course, these changes went on for many years, continually reviewed and refined.

You wrote about transforming the mental hospital and bringing in non-psychiatric activities. Were you influenced in that by the ideas of Thomas McKeown?

Very much so. He was working in Birmingham at the time and conceived the idea that everyone who was ill, whether acutely or chronically, and had to have hospital treatment, should be under one roof - separation into acute and chronic hospitals was a poor solution in his view. He pointed out the attraction for staff of acute facilities and the difficulties of recruitment in the chronic areas. At Lancaster Moor, when we had brought down the patient population fairly substantially, we found ourselves with some empty wards, even after reducing ward numbers, and many excellent hospital facilities, such as catering, cleaning, X-rays, and pathology, which could be used for other purposes. We suggested that the surplus could be used to supplement the acute medical and surgical facilities in Lancaster, and an acute medical unit, a neuro-surgical unit, an ophthalmic department with beds, and an orthopaedic ward were successfully established with us. The total was about 120 beds, which was nearly half that of the general hospital. In another part of Lancaster Moor, we established a children's psychiatric unit, with out-patient, day care, and in-patient facilities. A subnormal unit north of Lancaster was disbanded and the Moor was able to produce a ward for 30 residents, with the nursing staff to supervise them. Eventually, yet another ward became the basis for an Alcoholism Centre, with an in-patient facility. With its mixture of acute, subacute, and long-stay patients, we had no doubt that we had established a comprehensive hospital of the Mckeown type, and hoped we had resolved some of the urgent local problems, especially on the general medical side.

I thought at the time that this idea, which seemed so attractive and so natural, would be widely taken up, but in fact, it seems to have been emulated very little in other parts of the country.

Many people, particularly patients, liked the facilities, but there was always a fairly vocal group, particularly of medical and nursing professionals, who disliked the idea of their patients being treated in a mental hospital environment. A more insidious supposition was that the production of these facilities in Lancaster Moor would 'put back' building plans for the new District General Hospital, whose conception was already mooted in those days. Quite a number of physicians were forthcoming about this in years to come. As a member of Regional Planning Groups for many years, though, I really couldn't see any evidence that this 'misfortune' had actually occurred. Though many reasons were put forward for our DGH delays, the McKeown Comprehensive Hospital wasn't a credible one.

When you came to the North West for the first time, in 1957, what was your general impression of the psychiatric scene in the region?

The old Manchester Regional Hospital Board had responsibility for four large hospitals for the mentally handicapped and five for the mentally ill, including Lancaster Moor. These hospitals constituted a massive responsibility, and there were also many other smaller facilities for the handicapped that had grown rather like Topsy. But one quickly identified the main regional thrust in the late 1950 s towards the formation of the psychiatric unit as part 
of the general hospital. Plans were extant even then for new hospitals, but none was considered without a psychiatric unit.

What did you feel about this DGH policy, which was practically unknown elsewhere then?

The proposition seemed ludicrously simplistic. For an average district, with about a quarter of a million population, take about 120 in-patient beds for psychiatry in a general hospital with modern facilities, produce an out-patients department, a day activity centre, and as much occupational and behavioural therapy as possible, staff it with appropriate medical and nursing, and ancillary staff, and the immediate psychiatric needs of the district can be adequately met. In time, attract a department of clinical psychology, and a service can be produced which will also teach and possibly do research. It was an arresting idea, and certainly a world away from the large mental hospital. As you know, these units were formed all over the North West: Oldham by Arthur Pool, a great believer in and advocate of this type of service, Ted Downham in Burnley, and others in Bolton, Blackburn, Blackpool, and other places. They were very successful, if you consider that in the 1960 s, virtually no psychiatric patient in Burnley or Blackburn was transferred or admitted to Whittingham Hospital, which was the lock-up mental hospital for that district. The 120-bed general hospital unit was coping well, with no immediate problems.

For a long time, I was intrigued, as many were, by the services in those areas for the elderly mentally ill. All the units quickly built up a modus vivendi with the District geriatric department, and the smooth relationship between these two disciplines was far more effective than the rest of us managed between a mental hospital and the DGH geriatric department. In part, Lancaster Moor tried to emulate the general hospital psychiatric units. We identified a 130-bed unit in the hospital grounds and it became our district unit, though in this case within a mental hospital. The objective was to use these beds for a catchment area ranging from LancasterMorecambe to Barrow/Ulverston and a little into West Yorkshire, containing about 200,000 people. For a time, it worked very well and of course helped in the run-down of the hospital population: beds in other parts would become vacant, but not occupied as they used to be. The idea lasted for a few years, but changes of staff, occasional shortage of personnel, and severe pressure from a catchment area which had well above the average in elderly infirm patients tended to breach the dam, and the lure of empty beds sometimes proved irresistible.

Was this idea taken up in other places?

At that time, a growing number of hospital-based staff were resolutely opposed to the idea. They maintained that no unit could possibly produce the rehabilitative facilities of the large or even mediumsized mental hospital.

\section{Was there interest at a national level?}

A steady stream of visitors came from the Regional Board, who of course were delighted with the idea, from the Ministry, and from various other Regions. But always, I seemed to sense that while interested in the central precept, they were astonished and negatively influenced by our small numbers of psychiatrists. I have no doubt that many felt our concept of such a unit was really a way to employ a miniscule medical staff to more effect.

Had you any idea how the policy of DGH psychiatric units came about, or why it happened in the Manchester Region and nowhere else at the time?

I could never find a single author. In the Board's Planning minutes, there was a reference to psychiatric units being "part of the Regional Board's plan for the psychiatric service since 1948". Wherever the idea came from, it was enthusiastically put into action by the Senior Administrative Medical Officer, Dr Marshall, and particularly by the Deputy SAMO, John MacKay, who masterminded the concept in all the early years that I was there.

When did your own involvement with the Regional Board begin?

I became a Member of the Board in 1959. This continued for 15 years and included nine as Chairman of the Statutory Nursing Committee.

\section{How did you see things evolving in the 1960s?}

People were envisaging a progressive all-round improvement in psychiatric services then. More general hospital psychiatric units were being planned, but a good deal of money was also spent on the improvement and refurbishment of the large institutions, and various efforts were directed towards producing more trained staff. At Manchester University, Professor Anderson and John Hoenig were also expanding the Department of Psychiatry, and this proved an attraction to many able young people who were anxious to pursue a career in psychiatry. There seemed to be a lot of enthusiasm. Different disciplines, like clinical psychology and occupational therapy, were also beginning to make their contribution, especially in the mental hospitals.

\section{Did you carry out much visiting yourself?}

When one was a member of a Regional Board, there were many opportunities for visiting, in all aspects of medical and health activity. For instance, the setting up of an occupational therapy school in Manchester occasioned a lot of visiting of established OT schools 
of any size and reputation, all over the UK. I also had a particular brief to acquire knowledge of nursing schools and practice and to make sure that recruitment to nursing was moving in the right way. In addition to this, of course, there was constant attendance at meetings of the RMPA, which later became the Royal College.

Did you travel overseas at all in a psychiatric capacity? Just after I left Bristol, I spent nine months in Canada at the University of Alberta Department of Psychiatry in Edmonton. Then, in 1966, I joined a small teaching group from WHO - general medicine, paediatrics, public health, and psychiatry - for three months in Hyderabad Ghandi \& Osmani Medical Colleges, India. For me this was more a learning than a teaching experience, but I hope that as a group, we managed to put across some ideas that were of use to them. Next, I was a member of the Butler Committee on Mentally Abnormal Offenders, and during the three years that this met, we had opportunities to visit most of the important prisons in the UK as well as in Sweden, Denmark, and Holland. I remember the expectation that some of us had at the prospect of visiting the Hersedvester Hospital, near Copenhagen, in which Dr Sturup had obtained unusual improvements in the treatment of psychopathic illness allegedly by the use of the indeterminate sentence'. Unfortunately, he had retired by the time we visited, and the indeterminate sentence was no longer a judicial possibility in Denmark.

In spite of this, we learnt a great deal about Scandinavian attitudes to the treatment of mentally ill offenders, and about their facilities, which were often, of course, in very new or upgraded accommodation. Generally, they offered a much more extensive, liberal, and sociological approach than we had in the UK. Finally, much later, when I had retired and was Chairman of a Health Authority, I joined a small group enquiring into the mental health services in South Australia, on behalf of the State Government. We spent about three months there, but in general, found that facilities were very good, although the psychiatric services as such were based on two mental hospitals in Adelaide. They were not too impressed with the results of the run-down of mental hospitals in the UK, which by 1983 were showing up the lack of adequate community care.

How did you come to be a member of the Butler Committee?

I haven't any idea, though I have always had an interest in legal matters. As Chairman of the Regional Board's nursing committee and also as a medical superintendent, I had plenty of practical experience in the legal aspects of medicine. I am presently expanding my interest by taking an $\mathrm{Ll} . \mathrm{B}$ as a 'mature' student, in my retirement.
Do you feel that the Committee's recommendations were as influential as they should have been?

No.

\section{Why was that?}

I think that the ideas were not all that immediately attractive to health authorities, especially that of secure units anywhere near mental hospitals, which had spent many years trying to disassociate themselves from the concept of 'security' in all its manifestations. When, half-way through its deliberations, the Committee felt the situation was bad enough for 'interim secure units' to be formed in each Region, and money for the purpose was extracted from the Treasury, even then nothing seemed to happen. Later, when this matter was investigated, it was discovered that some regions had spent the money on "more urgent matters". As you know, quite a number of such facilities have now been established and are proving very worthwhile - I am thinking particularly of the ones at Salford and Wakefield. But overall, I would have thought that the Butler report did have some eventual practical value and can be regarded as an authoritative medico-legal source.

What was your impression of Butler himself?

I had a great admiration for him. He was an encyclopaedia of information, which he put over with consummate skill and a great deal of charm. At the same time, he kept the Committee on its toes. I couldn't imagine his Parliamentary Party not voting for him as leader, had the voting been a straightforward democratic procedure, as it is at present.

Did you have any other involvement with national bodies like that?

I was a member of the Parole Board for about two years, but unfortunately had to resign when I became Chairman of Lancaster Health Authority. Being a member of that Board is no sinecure, and it was impossible to combine the casework involved in that with introducing a new Health structure, with all its inseparable early problems. The Parole Board was an extraordinarily stimulating experience, though, and a very disciplined way of keeping professional people, especially medical ones, on their toes.

As a medical superintendent, how did you feel about the 'Oedipal' movement of the late ' $50 \mathrm{~s}$ and ' $60 \mathrm{~s}$ to abolish superintendents?

In general, I had no doubts that it was the right direction in which to go, although a close association with Hemphill at Bristol showed how much a person in that position could influence the work of the hospital, often in a very positive way. The position led to close contacts with Regional and Management Committee personnel, as well as with administrators, 
often informally. The opportunities for putting forward ideas and plans that could have a positive effect on psychiatry were endless, and no superintendent could be ignored for long. Consultant psychiatrists have rarely been in this sort of position, but it is true that for unfathomable reasons, medical superintendents often had an unassuageable compulsion to concern themselves with cases under the care of other consultants, and this was by no means limited to legal problems. For years, this kind of activity was a bone of contention. In the end, with increasing liberalisation everywhere, it seemed natural to change the designation to Medical Director, which pleased the administrators, and finally to discard the post altogether when the last incumbent retired. My consultant colleagues were competent people and certainly didn't require another consultant to give them constant unsolicited advice on how to treat their patients.

When you changed from primarily a psychiatric role to a more general role as Chairman of the Health Authority, how did that affect you?

I felt very honoured. I had spent many years in Lancaster, had been on the Regional Board, and later was Vice-Chairman of the Lancaster Area Health Authority - that totally unnecessary administrative tier, set up in 1974 and forever associated with Keith Joseph. I believed that I had the knowledge to do the job, particularly as the responsibility included the two large institutions - for mental handicap and mental illness - whose resources and needs would have to be balanced by the general side, including three general hospitals and many other out-patient facilities. It was a matter of balance, but the acute sector was always under pressure, whether from the surgical, the medical, or the midwifery sides. 'Fencing in' the monies that had been regionally and nationally earmarked for the 'cinderella' services mental handicap, mental illness, and geriatrics, wasn't easy and was often made more difficult by what I can only describe as a paucity of development plans of any sort from the mental handicap and psychiatric side. Even the slow evolution of the community care concept wasn't sufficient to balance the all-absorbing appetite of the general side for ever more finance.

What changes did you see in the services during the time of your Chairmanship?

A very definite increase in facilities for patients in all fields: for instance, a new midwifery department, increased surgical facilities, and diagnostic radiology improvements. Above all, new departments for geriatric medicine on the grounds of the local general hospitals in both Lancaster and Morecambe. More consultants were appointed, the nursing administration rationalised, and the establishment of a pri- vate 30-bed Nuffield unit concentrated our minds on our relationship with the private sector. As far as my old interests lay, the Moor Hospital was continuing, as all similar places were, to run down its patient population.

As an authority, we had laid down the axiom that patients from the psychiatric or mental handicap hospitals should not be transferred to community care facilities until these were at least up to the standard of care which they had in the hospital. When complaints about inadequate community care came rolling in, we constantly reiterated this policy, and no staff or patients would have remained in any doubt about it - we expected patients to remain in hospital if no appropriate community care was available. We believed that neither the Region nor Department of Health could quarrel with this, in spite of the idea of abolishing mental hospitals and having everybody in community care as soon as possible.

How do you think psychiatrists should respond to that situation?

If they believe that community facilities, including hospital back-up are tenuous or seriously lacking, I hope they would not agree to any discharge until the situation has improved. Nursing staff, clinical psychologists, occupational therapists, and social workers are of course invaluable people, but consultant psychiatrists should be able to take a 'total' view of the patient's problems and his or her future. In many places, the disastrous results of poor community care, with homelessness of ex-mental hospital patients, must surely be a considerable source of concern.

Have you any views on the changes that are happening in the NHS?

The changes in general practice appear to me no more than a progression of existing activities - for instance, a high level of immunisation, which many GPs have been achieving for years. On the other hand, so far as hospital services are concerned, I think we should, as a profession, have pressed harder and more single-mindedly for pilot schemes in various parts of the country.

Did you have any opportunity for any research in the 1960 s and 70 s?

Apart from my time in Canada, I have not worked in any district in which sustained research in psychiatry was possible, since I left Bristol, where a great deal was going on. Unless there is an adequate number of staff, serious applied research is impossible for the majority of us. Sometime during the 1960 s, the Superintendent Engineer at Lancaster Moor, built a 'silent room', with appropriate support areas, to look at the effects of perceptual isolation or sensory deprivation. The structure was excellent, with the sound 
difference level rising to $82 \mathrm{~dB}$ at $10,000 \mathrm{c} / \mathrm{s}$. We were able to produce three or four papers on the effects on volunteers, who included medical and nursing staff and a few patients, of staying in the room for varying times. The effects of isolation on volunteers taking psychomimetic drugs such as phencyclidine were also recorded. But such an excellent facility required a great deal more application and consistent work than we were ever able to give it, with our very limited staff. Quite simply, it was in the wrong place: it should have been in a University Department of Psychiatry. Professor Kenna from Manchester was able to use it for a while with medical students and Professor Jenner from Sheffield also, but the consistency of work required was never forthcoming - it was too far away. Otherwise, my contribution was mainly in the field of applied social psychiatry and reporting occasional interesting medical cases with associated psychological sequelae.

Did the coming of the University of Lancaster make such a difference?

Unfortunately no. The Department of Psychology was not initially engaged in work with obvious clini- cal associations, and at the time, we were concerned with building up a hospital and later a District Clinical Psychology Service. I hope there may be a closer association between the two in the future.

Any current concerns about our services?

I think there should still be a lot of concern about long-stay residents in what remains of the old mental hospitals. Most of them have been there for years, and I still believe that consultant psychiatrists should be mainly responsible for their overall supervision. Yet some colleagues apparently don't spend as much time as perhaps they should on assessing these patients' potential, if any, and gauging their abilities to live outside the community. In various capacities, I have read documents on ex-patients, giving the views of various people about their prognosis outside hospital, but for whatever reason, very few carried an opinion from a psychiatrist. If psychiatrists are being by-passed or ignored in this situation of running down the large hospitals, then their voices and objections should more clearly be heard. If this isn't a medical issue, then I don't know what is.

\section{Concepts of Mental Disorder $A$ continuing debate}

\section{Edited by Alan Kerr and Hamish McClelland}

Foreword, Professor Kenneth Rawnsley. Introduction, Dr Alan Kerr and Dr Hamish McClelland. The major functional psychoses: are they independent entities or part of a continuum? Professor Robert E. Kendell. Critique of the concept of 'unitary psychosis', Professor Sir Martin Roth. The failure of the Kraepelinian binary concept and the search for the psychosis gene, Dr Timothy J. Crow. The congenital and adult-onset psychoses, Professor Robin Murray and Dr Eadbhard O'Callaghan. Affective symptoms in schizophrenia, Professor Steven R. Hirsch. An American perspective, Professor Gerald Klerman. A European perspective, Professor Erik Strömgren. The affective disorders, Professor Myrna M. Weissman. Unitary psychosis and the psychiatry of old age, Professor David Kay. Neuroses and personality disorders, Dr Peter Tyrer. Nosology and neurosis, Dr Philip Snaith $£ 7.50$, pp. 160, ISBN 0902241389

\section{GASKELL Royal College of Psychiatrists}

